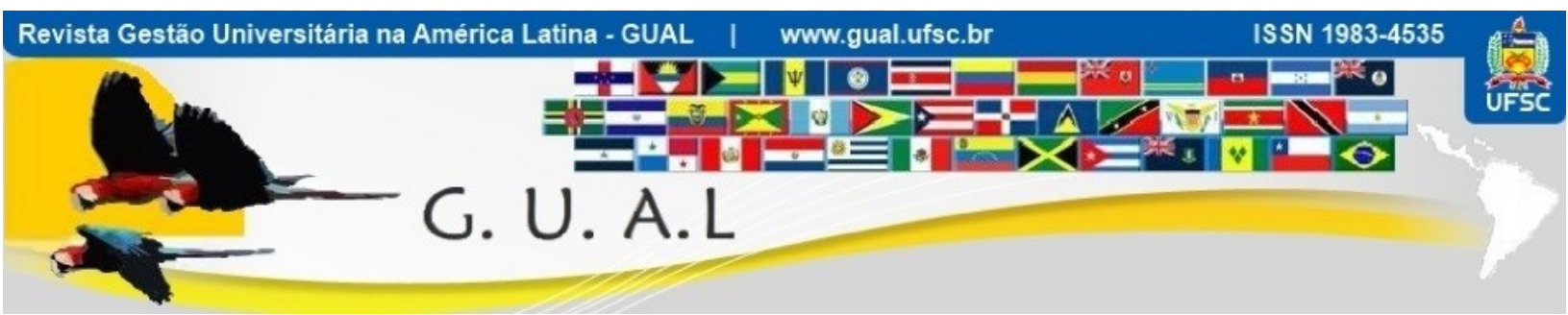

DOI: http://dx.doi.org/10.5007/1983-4535.2017v10n4p204

\title{
PLANO DE GESTÃO DE LOGÍSTICA SUSTENTÁVEL E SEUS INDICADORES: O CONTEÚDO MÍNIMO DE DIVULGAÇÃO, CONSCIENTIZAÇÃO E CAPACITAÇÃO NAS UNIVERSIDADES FEDERAIS BRASILEIRAS
}

\section{SUSTAINABLE LOGISTICS MANAGEMENT AND ITS INDICATORS: CONTENT OF DISCLOSURE, AWARENESS AND TRAINING AT BRAZILIAN FEDERAL UNIVERSITIES}

Samyra Cordeiro Franco, Mestre Universidade Federal de Mato Grosso do Sul - UFMS samyra scf@hotmail.com

Rosamaria Cox Moura Leite, Doutora Universidade Federal de Mato Grosso do Sul - UFMS rosamariamouraleite@,gmail.com

Milena Missiano Cameron, Mestre Universidade Federal de Mato Grosso do Sul - UFMS milocamimica@hotmail.com

José Carlos de Jesus Lopes, Doutor Universidade Federal de Mato Grosso do Sul - UFMS jose.lopes@ufms.br

Vera Luci de Almeida, Doutora Universidade Federal da Grande Dourados - UFGD veraalmeida@ufgd.edu.br

Recebido em 25/novembro/2016

Aprovado em 16/outubro/2017

Sistema de Avaliação: Double Blind Review

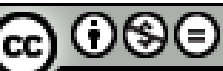

Esta obra está sob uma Licença Creative Commons Atribuição-Uso. 


\title{
RESUMO
}

O objetivo deste estudo é identificar as práticas desenvolvidas pelas Universidades Federais Brasileiras (UF's) relacionadas ao conteúdo mínimo de Divulgação, Conscientização e Capacitação (DCC), de seus Planos de Gestão de Logística Sustentável (PLS) e seus respectivos indicadores. A norma que trata do PLS exige a incorporação de quatro conteúdos mínimos, quais sejam: atualização do inventário que tenham um menor impacto ambiental para substituição; práticas de sustentabilidade e racionalização do uso de materiais e serviços; responsabilidades, metodologia de implementação e avaliação do plano e, por fim, as ações de DCC. Contudo, neste estudo, são tratadas apenas as ações de DCC. A fim de alcançar o objetivo proposto, foi desenvolvida uma pesquisa qualitativa, com base em estudos bibliográficos e documentais. Os resultados demonstram que, possivelmente, por questões culturais, a maioria dos gestores públicos brasileiros dos PLS das UF`s possui dificuldades em implantar o Plano e publicar seus Relatórios de Acompanhamento. Ficou evidente o desconhecimento sobre a importância de indicadores, como instrumento de monitoramento.

Palavras-chave: Administração Pública. Sustentabilidade. Instituições de Ensino Superior. Meio Ambiente. Justiça Ambiental.

\begin{abstract}
The objective of this study is to identify the practices developed by Brazilian Federal Universities related to the Disclosure, Awareness and Training (DAT) minimum content and indicators of their Sustainable Logistics Management Plans. The Sustainable Logistics Management Plans requires the incorporation of four minimum contents, which are: inventory updates that have a lower environmental impact for replacement; sustainability practices and rationalization of the use of materials and services; responsibilities, methodology of implementation and evaluation of the plan and, finally, the actions of DAT. However, in this study, we have only considered DAT actions. In order to reach the proposed objective, a qualitative research was developed, based on bibliographical studies and documentaries. The results show that, possibly due to cultural issues, the majority of Brazilian public managers at UF 's PLS have difficulty implementing the Plan and publishing follow-up reports. The lack of knowledge about the importance of indicators as a monitoring instrument became evident in our research.
\end{abstract}

Keywords: Public Administration. Sustainability. Federal University. Higher Education Institutions. Environment. Environmental Justice. 


\section{INTRODUÇÃO}

No Brasil, como condição de construir um novo modelo de cultura nos órgãos e entidades públicas que fomente a sustentabilidade, o Ministério do Meio Ambiente (MMA) criou a Agenda Ambiental na Administração Pública (A3P), de adesão voluntária, tendo como foco incitar a adoção da gestão socioambiental pelos gestores públicos (MMA, 2009). A partir de então, foi criado o Plano de Gestão de Logística Sustentável (PLS), com o intuito de tornar as ações da Administração Pública e dos órgãos públicos envolvidos mais sustentáveis. Os documentos específicos que compõem os PLS's e que serão adotados nesta pesquisa são o Decreto $n^{\circ} 7.746$, de 5 de junho de 2012, da Presidência da República do Brasil e a Instrução Normativa $\mathrm{n}^{\mathrm{o}}$ 10, de 14 de novembro de 2012, do Ministério do Planejamento, Orçamento e Gestão.

O Plano de Gestão de Logística Sustentável, doravante a ser denominado apenas como PLS, é o mecanismo de planejamento que permite que os órgãos públicos brasileiros e as empresas estatais estabeleçam práticas de sustentabilidade, almejando-se, assim ao novo padrão de cultura direcionado para a Administração Pública (BRASIL, 2012b). Ao longo do corpo textual do documento instrui que cada Plano deverá conter sete temas mínimos. São eles: 1) água e esgoto; 2) coleta seletiva; 3) compras e contratações sustentáveis; 4) deslocamento de pessoal; 5) energia elétrica; 6) material de consumo; e 7) qualidade de vida no trabalho. Ainda de forma complementar ao Plano, similarmente, exige-se que envolva cinco conteúdos mínimos, tais como: 1) atualização do inventário de bens materiais do órgão ou entidade e equivalentes de menor impacto ambiental para substituição; 2) práticas de sustentabilidade e racionalização do uso de materiais e serviços; 3) responsabilidades; 4) metodologia de implementação e avaliação do plano; e 5) ações de divulgação, conscientização e capacitação (DCC).

As Universidades Federais (UF's) estão incluídas nas referidas normativas e têm importância singular por possuírem grande quadro de servidores das carreiras TécnicoAdministrativos e docentes do Magistério Superior, além do corpo discente. Medeiros Junior (2004) coloca que as Instituições de Ensino Superior (IES's) possuem papel singular, pois podem impulsionar o desenvolvimento econômico, geram novos conhecimentos, transmitem experiências e possibilitam mudança de comportamento. $\mathrm{O}$ referido autor complementa que para a universidade ter responsabilidade social, deverá possuir objetivos, missão e compromissos de utilizar materiais que não agridam o meio ambiente e que desenvolvam 
preocupação com o ser humano em sua totalidade. Tauchen (2007) reitera que as IES's possuem responsabilidade social voltada para os discentes, funcionários e a comunidade ao capacitar pessoas conscientes da importância de assegurar a sustentabilidade das futuras gerações. Petrelli e Colossi (2006) advertem que nem sempre a sociedade percebe a função transformadora e de desenvolvimento social que as IES's possuem. Para os autores, é necessário que as IES's divulguem suas atividades para que todos os interessados possam conhecê-la e avaliar seus resultados.

Existem manuais que auxiliam os gestores em desenvolver ações em determinados temas mínimos do PLS. Para Lopes (2007), cartilhas e manuais são instrumentos uteis para resolver ou diminuir problemas. No entanto, não foi encontrado pelo levante bibliográfico realizado um documento que tivesse como objetivo auxiliar no desenvolvimento do requisito mínimo DCC.

Neste contexto, o objetivo deste estudo é identificar as práticas das Universidades Federais relacionadas ao requisito mínimo de Divulgação, Conscientização e Capacitação (DCC), do Plano de Gestão de Logística Sustentável e seus respectivos indicadores. Para alcançar este objetivo, o corpo textual desta investigação é composto por esta parte introdutória, seguida do referencial teórico que trata da sustentabilidade, das normativas legais, ações, programas e indicadores. Na seção imediata é explicado o método de pesquisa aplicado que propiciou aos resultados e discussões colocadas, a seguir. Por último estão as considerações finais e as referências. Sendo assim e a partir dessa oportunidade, acredita-se que os resultados frutos desta pesquisa possam contribuir com a literatura no que diz respeito às ações compreendidas no conteúdo mínimo DCC e as possíveis formas de mensurar seus resultados direcionados às Universidades Federais.

\section{DISCUSSÕES TEÓRICAS}

\subsection{SUSTENTABILIDADE E O PAPEL DO ESTADO: LEIS, AÇÕES E PROGRAMAS}

O Brasil possui leis ambientais nos mais diversos segmentos. Também há uma lei específica que trata das infrações e punições, denominada Lei de Crimes Ambientais de número 9.605, de 12 de fevereiro de 1998 (BRASIL, 1998). Como o cerne da pesquisa são as ações de Divulgação, Conscientização e Capacitação, foram agrupadas as principais legislações ambientais por área de conhecimento, quais seja: uso racional de recursos naturais e bens públicos, gestão de resíduos, qualidade de vida no trabalho (QVT), educação ambiental 
e licitações sustentáveis. Tais legislações são regras que cabem ao Poder Público e à sociedade.

No Quadro 1 são apresentadas as principais normas que regem as práticas de sustentabilidade no país. Ao analisá-lo, percebe-se um processo evolutivo de ações para aplicar melhores maneiras para reduzir o impacto sobre o meio ambiente, que vai desde a atenção para o uso e desfazimento de material utilizado na Administração Pública, até a elaboração e implantação do PLS, normativa para mudar a cultura dos servidores públicos dos órgãos, tornando suas práticas e tomadas de decisões mais sustentáveis. Em síntese, para que haja mudança cultural é necessário rever a maneira de se desfazer dos materiais utilizados, bem como procurar adquirir, no ato da compra, materiais que não agridam o meio ambiente, além de reduzir o consumo de energia e a separação correta do lixo, dentre outras.

Além das leis específicas sobre a questão ambiental, o Art. 225 da Constituição Federal, de 1988, buscou integrar ações do poder público e sociedade, como também a preservação e defesa do meio ambiente. Nele trata-se dos direitos a usufruir do meio ambiente ecologicamente equilibrado, bem de uso comum do povo e qualidade de vida (BRASIL, 1988).

Quadro 1 Legislação ambiental aplicada à Administração Pública

\begin{tabular}{|c|c|}
\hline Leg & Teor \\
\hline $\begin{array}{l}\text { Uso racional de } \\
\text { recursos naturais e } \\
\text { bens públicos }\end{array}$ & $\begin{array}{l}\text { Decreto } 99.658 \text { (BRASIL, 1990a). Regulamenta, no âmbito da Administração } \\
\text { Pública Federal o reaproveitamento, a movimentação, a alienação e outras } \\
\text { formas de desfazimento de material; } \\
\text { Lei } 10.295 \text { (BRASIL, 2001). Dispõe sobre a Política Nacional de Conservação } \\
\text { e Uso Racional de Energia e dá outras providências; } \\
\text { Decreto } 4.131 \text { (BRASIL, 2002a). Trata de medidas emergenciais para a } \\
\text { redução de consumo de energia elétrica na Administração Pública Federal; } \\
\text { Lei } 12.187 \text { (BRASIL, 2009a). Refere-se à Política Nacional sobre Mudança no } \\
\text { Clima (PNMC). Um dos objetivos é que o ocorra o desenvolvimento } \\
\text { econômico-social em consonância com a proteção do sistema climático global; } \\
\text { Portaria Interministerial no } 244 \text { de } 2012 \text { (MPOG, 2012). Trata do Projeto } \\
\text { Esplanada Sustentável (PES). }\end{array}$ \\
\hline Gestão de Resíduo & $\begin{array}{l}\text { Decreto 5.940 (BRASIL, 2006b). Trata da separação e destinação dos resíduos } \\
\text { recicláveis descartados; } \\
\text { Lei } 12.305 \text { (BRASIL, 2010a). Trata da Política Nacional de Resíduos Sólidos; } \\
\text { Decreto 7.404 (BRASIL, 2010d). Regulamenta a Lei no } 12.305 \text {, de } 2 \text { de agosto } \\
\text { de 2010, que institui a Política Nacional de Resíduos Sólidos, cria o Comitê } \\
\text { Interministerial da Política Nacional de Resíduos Sólidos e o Comitê } \\
\text { Orientador para a Implantação dos Sistemas de Logística Reversa; } \\
\text { Resolução CONAMA no } 275 \text { (BRASIL, 2001b). Estabelece o código de cores } \\
\text { para os diferentes tipos de resíduos. }\end{array}$ \\
\hline $\begin{array}{l}\text { Qualide } \\
\text { no Trab }\end{array}$ & $\begin{array}{l}\text { Lei } 8.112 \text { (BRASIL, 1990b). Os servidores receberão adicionais por } \\
\text { executarem atividades insalubres, perigosas ou penosas. }\end{array}$ \\
\hline
\end{tabular}




\begin{tabular}{|c|l|}
\hline $\begin{array}{c}\text { Educação } \\
\text { Ambiental }\end{array}$ & Lei 9.795 (BRASIL, 1999): Trata da educação ambiental. \\
\hline \multicolumn{1}{|c|}{ Capacitação } & $\begin{array}{l}\text { Decreto 5.707 (BRASIL, 2006a). Institui a Política e as Diretrizes para o } \\
\text { Desenvolvimento de Pessoal da administração pública federal direta, } \\
\text { autárquica e fundacional. }\end{array}$ \\
\hline $\begin{array}{l}\text { Lei 8.666 (BRASIL, 1993). Normas gerais sobre licitações e contratos } \\
\text { administrativos. } \\
\text { Lei } 10.520 \text { (BRASIL, 2002b). Trata da modalidade de licitação denominada } \\
\text { pregão. } \\
\text { Lei 12.349 (BRASIL, 2010b). Inclui a promoção do desenvolvimento nacional } \\
\text { sustentável como quesito para os processos licitatórios na administração } \\
\text { pública. } \\
\text { IN no 01/2010-MPOG (Brasil, 2010c). Critérios de sustentabilidade ambiental } \\
\text { na aquisição de bens, contratação de serviços ou obras pela Administração } \\
\text { Pública Federal; } \\
\text { Decreto 7.746 (BRASIL, 2012a). Promover o desenvolvimento nacional } \\
\text { sustentável por meio das contratações realizadas pela administração pública } \\
\text { federal direta, autárquica e fundacional; } \\
\text { IN no } 10 / 2012-M P O G \text { (BRASIL, 2012b). Estabelece regras para elaboração dos } \\
\text { Planos de Gestão de Logística Sustentável. }\end{array}$ \\
\hline Lei 9.605 (BRASIL, 1998). Trata de infrações e punições. \\
\hline Crimes Ambientais
\end{tabular}

Fonte: Organizado pelos autores.

Como forma de tornar os órgãos públicos que compõem a Administração Pública conscientes, desenvolvendo um pensamento voltado para o não desperdício, a preservação dos recursos da natureza e a atenção para uma cultura de gestão sustentável, o Ministério do Meio Ambiente elaborou, em 2009, a Agenda Ambiental na Administração Pública (A3P), de adesão voluntária. Ao ter contato com a A3P, é possível observar que o corpo normativo traz como diretriz as sugestões do Capítulo 4 da Agenda 21, que trata das mudanças dos padrões de consumo. Também tem como princípios os 5 R's (repensar, reduzir, reaproveitar, reciclar e recusar) a consumir produtos que gerarão impactos ambientais negativos (MMA, 2009).

Em 2011, o Plenário do Tribunal de Contas da União publicou o Acórdão 1.752 (BRASIL, 2011). No item 9.9, recomenda-se que o Ministério do Planejamento, Orçamento e Gestão incentivasse os órgãos e instituições públicas federais a estabelecer programas direcionados para o uso racional dos recursos naturais e também campanhas de conscientização para os usuários. Em seguida, elaborou-se o Projeto Esplanada Sustentável (PES), instituído através da Portaria Interministerial no 244, de 06 de junho de 2012. O PES é regularizado pelo Ministério do Planejamento, Orçamento e Gestão e vinculado com o Ministério do Meio Ambiente, Ministério de Minas e Energia e Ministério de Desenvolvimento Social e Combate a Fome (MPOG, 2012). De acordo com Art. $1^{\mathrm{o}}$ do Ministério do Planejamento, Orçamento e Gestão (MPOG, 2012), sua finalidade é integrar 
ações que visam à melhoria da eficiência no uso racional dos recursos públicos e à inserção da variável socioambiental no ambiente de trabalho.

Em seguida, como medida também direcionada para a Administração Pública, foi elaborado o Plano de Gestão de Logística Sustentável (PLS), normatizado pelo Decreto 7.746/2012, que estabeleceu critérios, práticas e diretrizes para que se promova o desenvolvimento nacional sustentável nas contratações em que a Administração Pública Federal realiza. Foi igualmente criada a Comissão Interministerial de Sustentabilidade na Administração Pública (CISAP), sendo esta com atribuições de natureza consultiva e permanente (BRASIL, 2012a). De acordo com o Art. 11 do referido Decreto, a CISAP tem por competência propor à Secretaria de Logística e Tecnologia da Informação (SLTI), regras para que sejam elaboradas ações de logística sustentáveis e Planos de Gestão de Logística Sustentáveis, assim como preceitos para que as aquisições, contratações, desfazimento e descartes sejam também sustentáveis. Ainda destaca que a CISAP deverá propor à Secretaria de Logística e Tecnologia de Informação que se façam estratégias de sensibilização e capacitação para servidores públicos para que o PLS seja feito de maneira correta, além de ressaltar ações para a divulgação de práticas sustentáveis (BRASIL, 2012a).

À vista disso, a SLTI elaborou a IN no 10/2012-MPOG, em que no Art. $2^{\circ}$ descreve o PLS como "processo de coordenação do fluxo de materiais, de serviços e de informações, do fornecimento ao desfazimento, que considera a proteção ambiental, a justiça social e o desenvolvimento equilibrado" (BRASIL, 2012b). O PLS possui conteúdos mínimos, que acordo com o Decreto 7.746/2012, Art. 16, I-IV, são:

Art. 16. A administração pública federal direta, autárquica e fundacional e as empresas estatais dependentes deverão elaborar e implementar Planos de Gestão de Logística Sustentável, no prazo estipulado pela Secretaria de Logística e Tecnologia da Informação, prevendo, no mínimo:

I - Atualização do inventário de bens e materiais do órgão e identificação de similares de menor impacto ambiental para substituição;

II - Práticas de sustentabilidade e de racionalização do uso de materiais e serviços;

III - responsabilidades, metodologia de implementação e avaliação do plano; IV - ações de divulgação, conscientização e capacitação (BRASIL, 2012a).

Conforme já colocado, para efeito desta pesquisa, será analisado apenas o conteúdo mínimo elencado no inciso IV, quais sejam as ações de Divulgação, Conscientização e Capacitação (DCC), voltadas para as Universidades Federais Brasileiras. Assim, o PLS é considerado uma ferramenta para que os órgãos ou entidades públicas possam estabelecer práticas de sustentabilidade e racionalização de gastos e processos na Administração Pública, 
possuindo prazos e metas (BRASIL, 2012b). Nesta direção, a IN nº10/2012-MPOG traz algumas definições em seu Art. $2^{\circ}$ incisos I, III, V e VIII:

Art. $2^{\circ}$. Para os fins desta Instrução Normativa, considera-se:

I - logística sustentável: processo de coordenação do fluxo de materiais, de serviços e de informações, do fornecimento ao desfazimento, que considera a proteção ambiental, a justiça social e o desenvolvimento econômico equilibrado;

$[\ldots]$

III - práticas de sustentabilidade: ações que tenham como objetivo a construção de um novo modelo de cultura institucional visando a inserção de critérios de sustentabilidade nas atividades da Administração Pública;

$[\ldots]$

V - coleta seletiva: coleta de resíduos previamente segregados conforme sua constituição ou composição;

$[\ldots]$

VIII - material de consumo: todo material que, em razão de sua utilização, perde normalmente sua identidade física e/ou tem sua utilização limitada a dois anos.

[...] (BRASIL, 2012b).

A IN $n^{0}$ 10/2012-MPOG traz outros conceitos aplicáveis rotineiramente na Administração Pública e busca a conscientização por meio da capacitação dos servidores, voltada para a questão ambiental. No artigo $8^{\circ}$ da referida Instrução são elencados os sete temas mínimos a serem desenvolvidos para cada PLS. São eles:

Art. 8. As práticas de sustentabilidade e racionalização do uso de materiais e serviços deverão abranger no mínimo, os seguintes temas:

I - material de consumo compreendendo, pelo menos, papel para impressão, copos descartáveis e cartuchos para impressão;

II - energia elétrica;

III - água e esgoto;

IV - coleta seletiva;

$\mathrm{V}$ - qualidade de vida no ambiente de trabalho;

VI - compras e contratações sustentáveis, compreendendo, pelo menos, obras, equipamentos, serviços de limpeza, de telefonia, de processamento de dados, de apoio administrativo e de manutenção predial; e

VII - deslocamento de pessoal, considerando todos os meios de transporte, com foco na redução de gastos e de emissões de substâncias poluentes (BRASIL, 2012b).

Diante destes dispositivos instrucionais, no Brasil, caberá a cada Universidade Federal (UFs) desenvolver e melhorar suas medidas, para que o cuidado com o meio ambiente se estenda para além do campus. Assim, os PLS's são utilizados para pôr em prática o que já foi determinado pelas legislações vigentes. Caso as UFs possuam todos os temas do PLS supracitados, deverão adotar indicadores como forma de mensuração, contendo nome, 
fórmula de cálculo, fonte de dados, metodologia de apuração e periodicidade de apuração (BRASIL, 2012b)

\subsection{INDICADORES}

De acordo com o Serviço Social da Indústria (2010, p. 11), os indicadores são "variáveis definidas para medir um conceito abstrato, relacionado a um significado social, econômico ou ambiental com a intenção de orientar decisões sobre determinado fenômeno ou interesse". Serve, portanto, como um instrumento, uma ferramenta de monitoramento e de acompanhamento evolutivo do indicador, comparando-os ao longo do tempo e estabelecendo parâmetros.

Hammond et al. (1995) definem duas características dos indicadores. A primeira, os indicadores quantificam informações para que seu significado seja facilmente evidente. A segunda, eles simplificam as informações sobre fenômenos complexos com o objetivo de melhorar a comunicação. Segundo o referido autor, os indicadores possuem importância à medida que reduzem a incerteza ao tomar decisões ou até mesmo ao facilitar o entendimento das melhores decisões; porém, para que isso aconteça, os gestores deverão considerá-los úteis e também utilizá-los. Admitindo assim como forma de definir e mensurar o desempenho da Administração Pública, o Ministério do Planejamento, Orçamento e Gestão elaborou o Guia Referencial para Medição do Desempenho na Administração Pública. O mesmo órgão público definiu indicadores como essenciais para o monitoramento e avaliação das organizações públicas diretas e indiretas, pois possibilita o acompanhamento do alcance das metas, progressos, qualidade, correção de possíveis problemas, necessidades de mudança, dentre outras possíveis necessidades (BRASIL, 2009b).

Para o Ministério também é importante a elaboração da fórmula de cálculo e a unidade de medida para o desenvolvimento de um indicador. A fórmula do indicador deverá ser compreensível e não apresentar dificuldade de cálculo ou de uso, permitindo comparação com valores determinados e assim auxiliar a tomada de decisão dos gestores. De acordo o Ministério do Planejamento, Orçamento e Gestão (BRASIL, 2009b) e o Serviço Social da Indústria (2010), as unidades de medida mais comuns são:

1) Indicadores simples: expressam um valor numérico atribuível à uma variável. Geralmente mede-se a eficácia, ou seja, a quantidade de produtos ou serviços entregues aos beneficiários. 
2) Indicadores compostos: neles há relação entre duas ou mais variáveis, podendo ser de quatro tipos: proporção ou coeficiente; porcentagem; razão ou índice; taxa.

Diante desses entendimentos, há de se admitir e considerar que os indicadores permitem prover gestões e planos de trabalhos que visem o sucesso dos propósitos organizacionais, uma vez que esses deverão ser orientados para os utilizadores, ou seja, serem úteis para público que se pretende alcançar com informações relevantes para a tomada de decisão de forma compreensível, bem como deverão ser relevantes para a política, não apenas em caráter técnico, devendo ser interpretado facilmente, além de serem altamente agregados (HAMMOND et. al, 2005).

\subsection{AS UF'S E O COMPROMETIMENTO COM A SUSTENTABILIDADE}

De acordo com o Decreto 5.205, de 2004, em seu Art. $1^{\circ}$, $\S 1^{\circ}$, as Instituições Federais de Ensino Superior (IFES's) são as Universidades Federais, Faculdades e Faculdades Integradas, Escolas Superiores e Centros Federais de Educação Tecnológica (BRASIL, 2004). Para fins desta pesquisa, serão consideradas apenas as Universidades Federais, doravante a ser denominada apenas de UF's. Severino (2007) ao tratar do papel da formação universitária, coloca que não apenas visando uma qualificada habilitação técnica, profissional e científica, ela deverá acrescentar o compromisso com a construção da cidadania e qualidade de vida humana e digna. Em outras palavras, a formação universitária deverá despertar aos formados uma nova consciência social. Delors (2004) acredita que as funções das universidades de pesquisa inovação, ensino, formação, educação permanente e cooperação internacional, cooperam, de forma integrada, para que se tenha o desenvolvimento sustentável. Para tanto, no entendimento de Marín (2011), as IFES's necessitam criar e disseminar novas formas de conhecimento ao repensar sua relação de ensino-aprendizagem, no sentido de melhorar o uso dos recursos para que resulte nos campis universitários modelos de gestão e incentivo de atitudes mais sustentáveis.

De acordo com Severino (2007), são três os objetivos do Ensino Superior: 1) Formar profissionais de diferentes áreas, utilizando a relação de ensino-aprendizagem, com a habilidade e competência técnicas; 2) Formar cientistas sociais, de acordo com a disponibilidade de métodos e conteúdos de conhecimento; e 3) Instrumentalizar a formação do cidadão, através da tomada de consciência. $\mathrm{O}$ autor complementa, dizendo que tudo isso deverá despertar no discente a consciência e contribuir para a vida em sociedade. Tauchen e 
Brandli (2006) afirmam que o desenvolvimento tecnológico oriundos dos ambientes das IES passa, inicialmente, e de forma necessária, pela educação ambiental do corpo docente e discente, associada à disseminação de informações, para que se alcance uma sociedade ambientalmente mais justa. Para Guimarães (2010), educar ambientalmente transpassa a ideia de apenas comunicar a população sobre a necessidade da preservação ambiental; mas, sobretudo, de criar mecanismos sociais permanentes de sensibilização de cada cidadãoconsumidor, ator social, tomadores de decisões para que todos estejam realmente sensíveis ao direito do equilíbrio natureza e sociedade, potencializando, assim a justiça social e ambiental, que são indissociáveis.

O paradigma da justiça ambiental parte da premissa ética que nenhum grupo de pessoas, independentemente de suas características sociais, de trabalho, renda, moradia, racial, deve suportar uma parcela desproporcional das consequências ambientais negativas, seja ela de natureza econômica, política e local, seja ela resultante da omissão do poder público (CAVEDON; VIEIRA, 2014). Ao destinar uma maior carga dos danos ambientais do crescimento econômico a uma parcela social de trabalhadores, população de menor renda, grupos raciais e sociais marginalizados e descriminados, sendo os mesmos mais vulneráveis, se entende este como um quadro de injustiça ambiental, como bem ensina Acserald (2002). A ideia de injustiça socioambiental tomaria como referência uma situação hipotética, onde todos os grupos sociais deveriam ter acesso igualitário aos recursos naturais: terra, ar e água. Com isso, a injustiça socioambiental poderia ser caracterizada de uma forma mais direta por uma desigualdade no acesso aos recursos naturais como ar, água e solo de melhor qualidade, ou indiretamente, por uma desigualdade no acesso às tecnologias e aos riscos associados a esses recursos (LEÃO, 2013).

Neste contexto, pressiona-se por intervenção por parte dos governos, no desenvolvimento e cumprimento de políticas públicas ou mesmo as normativas punitivas para que se potencialize o reequilíbrio do acesso aos recursos e minimize os riscos ambientais, gerando uma economia e uma sociedade que opere em um nível socioambiental justo e eficiente. (ACSELRAD; HERCULANO; PÁDUA, 2004).

\section{MÉTODO DE PESQUISA}

$\mathrm{Na}$ busca de alcançar o objetivo anunciado na parte introdutória, depois dos levantamentos bibliográficos e análises documentais, foi realizada a busca nas páginas 
eletrônicas oficiais das UF's brasileiras, a fim de descobrir quais delas divulgaram o PLS. Optou-se pela pesquisa via internet, devido à normativa que rege o PLS, a qual se exige que os Planos sejam publicados, nos sites dos respectivos órgãos ou entidades. Após essa busca, resultou que das 63 UF's do país, apenas 22 divulgaram o Plano. Para as 41 UF's que não disponibilizaram o PLS, a equipe de pesquisadores fez contatos, através das ferramentas fale conosco, ouvidoria e também pelos e-mails institucionais para tentar compreender quais, de fato, ainda não haviam elaborado.

Assim sendo, obteve-se o retorno de 11 UF's, esclarecendo que 7 ainda não ainda possuíam o PLS e 4 estavam em fase de elaboração. As demais 30 UF's não retornaram aos contatos. A partir de então, para os 22 Planos existentes, foram identificadas e analisadas as ações de DCC das mesmas, como se verá a seguir. Para classificar as ações dos DCC identificadas, utilizaram-se, inicialmente, os sete temas mínimos, dispostos na IN n⿳010/2012MPOG, de acordo com o Art $8^{\circ}$ incisos de I a VII (BRASIL, 2012b). Apenas relembrando: água e esgoto, coleta seletiva, compras e contratações sustentáveis, deslocamento de pessoal, energia elétrica, material de consumo e qualidade de vida no trabalho. Além das referidas nomenclaturas, duas foram criadas: Educação Ambiental e Plano. Foram elaboradas essas duas categorias, devido à dificuldade em conceituar todas as práticas de DCC, nas sete áreas dos PLS mencionadas. Assim, as ações foram classificadas em nove categorias.

Outra etapa trouxe à luz a importância dos indicadores relacionados às ações de DCC das UF's. Anterior a essa coleta de dados, o projeto do estudo foi submetido ao Comitê de Ética em Pesquisa Envolvendo Seres Humanos/UFMS (CEP/UFMS), que solicitou que as chefias dos gestores ou coordenadores do Plano das UF's participantes deveriam autorizar o procedimento de coleta de dados. Dessa forma, os pedidos de autorização foram direcionados às 22 UF's, que tinham seus PLS's publicados em seus respectivos sites institucionais.

Foram elas: Universidade Federal do Ceará (UFC); Universidade Federal de Ciências da Saúde de Porto Alegre (UFCSPA); Universidade Federal Rural do Semi Árido (UFERSA); Universidade Federal da Fronteira Sul (UFFS); Universidade Federal de Goiás (UFG); Universidade Federal da Grande Dourados (UFGD); Universidade Federal do Maranhão (UFMA); Universidade Federal de Mato Grosso do Sul (UFMS); Universidade Federal do Oeste do Pará (UFOPA); Universidade Federal da Paraíba (UFPB); Universidade Federal Rural da Amazônia (UFRA); Universidade Federal do Recôncavo da Bahia (UFRB); Universidade Federal de Roraima (UFRR); Universidade Federal de Sergipe (UFS); 
Universidade Federal de Santa Catarina (UFSC); Universidade Federal de São João del Rei (UFSJ); Universidade Federal de Santa Maria (UFSM); Universidade Federal do Tocantins (UFT); Universidade Federal do Triângulo Mineiro (UFTM); Universidade Federal dos Vales do Jequitinhonha e Mucuri (UFVJM); Universidade Federal de Alfenas (UNIFAL) e Universidade Tecnológica Federal do Paraná (UTFPR).

Foi obtido retorno de 7 das 22 UF's consultadas. Com o Parecer Consubstanciado emitido pelo CEP/UFMS, procedeu-se na elaboração dos questionários direcionados para as UF's. Neste trabalho as 6 foram identificadas como: Universidade 1 (UF1), Universidade 2 (UF2), Universidade 3 (UF3), Universidade 4 (UF4), Universidade 5 (UF5), Universidade 6 (UF6) e Universidade 7 (UF7). O período da pesquisa foi entre novembro de 2015 a abril de 2016. Como critério de inclusão na amostra, foi considerada a devolução dos questionários devidamente preenchidos e assinados. Desta forma, as UF's que não responderam os questionários dentro do prazo, foram automaticamente excluídas da pesquisa. Com a posse dos questionários devidamente preenchidos, realizou-se sua análise, tendo em vista o referencial teórico e a legislação em vigor. O fluxograma da Figura 1 sintetiza as etapas da pesquisa e definição da amostra.

Figura 1 Etapas da pesquisa

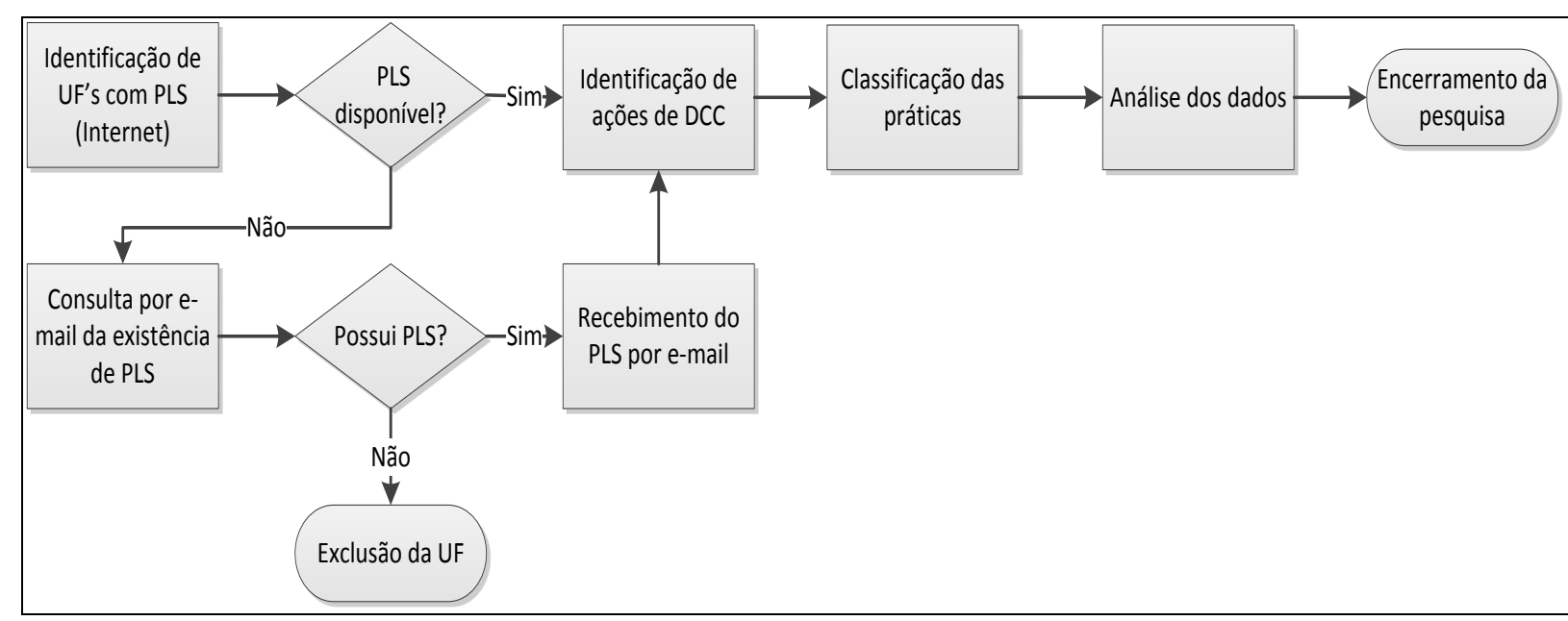

Fonte: Elaborado pelos autores 


\section{ANÁLISE E DISCUSSÕES}

\subsection{PLANOS DE GESTÃO DE LOGÍsTICA SUSTENTÁVEL PUBLICADOS E AS AÇÕES DE DCC}

O intuito deste tópico é apresentar os números relacionados aos PLS's das UF's e suas ações de DCC. A Tabela 1 demonstra o percentual de UF's que publicou o PLS e também qual região do país possui o menor número de adesão.

Tabela 1 Número de UF's por região e que publicaram o PLS

\begin{tabular}{lrccc}
\multicolumn{1}{c}{ Região } & Qtd (UF) & Qtd (PLS) & $\begin{array}{c}\text { \% de UF com } \\
\text { PLS/Região }\end{array}$ \\
\hline Centro-Oeste & 5 & 3 & $60 \%$ \\
Nordeste & 18 & 6 & $33 \%$ \\
Norte & 10 & 4 & $40 \%$ \\
Sudeste & 19 & 4 & $21 \%$ \\
Sul & 11 & 5 & $45 \%$ \\
\hline Total & 63 & 22 & - \\
\hline
\end{tabular}

Fonte: Elaborada pelos autores.

Como se vê, a região Centro-Oeste possui cinco UF's e três delas adotaram o PLS, ou seja, $60 \%$ da região possuem o Plano. A região Sul possui onze UF's e cinco delas possuem o PLS, gerando um percentual de $45 \%$. A região Norte possui dez UF's e quatro implantaram o PLS, com um percentual de $40 \%$. A região Nordeste possui dezoito UF's e seis delas possuem o PLS, gerando um percentual de 33\%. Por fim, a região Sudeste, possui dezenove UF's e é a que menos aderiu ao PLS, com o quantitativo de apenas quatro, gerando um percentual de 21\%. De acordo com a IN nº10/2012-MPOG (BRASIL, 2012b), o PLS é importante para estabelecer práticas sustentáveis e para racionalizar os gastos e processos dos órgãos governamentais, além de estimular a transparência e acesso à informação. As normas que regem o PLS discriminam o prazo de cento e oitenta dias contados, a partir da data de sua publicação, para que toda a Administração elabore e publique seus respectivos Planos. Por conseguinte, adotar o PLS é uma obrigação da Administração Pública Federal direta, autárquica, fundacional e das empresas estatais dependentes. Porém, a partir dos dados coletados, percebe-se que o PLS não abrangeu todas as UF's do país. Os dados mostram a grande demanda que a Administração Pública possui para se alinhar na sustentabilidade e à justiça socioambiental. Uma possível razão para a não adesão total de todas as UF's ao PLS é a recente entrada em vigor das referidas normas. 
A Tabela 2 classifica os tipos de ações de DCC adotadas pelas UF's, que publicaram seus PLS, bem como seus respectivos percentuais. Ao classificá-las foram encontradas 317 práticas de sustentabilidade, agrupadas de acordo com o Art. $8^{\circ}$, Incisos de I ao VII, da IN 10/2012/MPOG, além de duas categorias criadas, denominadas de Plano e Educação Ambiental, a fim de ajudar na interpretação da Tabela 2. O Plano tem como objetivo a gestão do PLS, tais como a criação de sites, divulgação de seminários, que tenham como tema o PLS, dentre outras. Já o conceito da categoria Educação Ambiental está de acordo com a Lei 9.795 de 1999, conhecida por Política de Educação Ambiental e que tem por fundamento a construção de valores sociais, conhecimentos, habilidades, atitudes e competências voltadas para a conservação do meio ambiente (BRASIL, 1999). Por exemplo: Divulgar as normas ligadas à sustentabilidade com o propósito de que sejam mais conhecidas e seguidas; exposição de banner sobre sustentabilidade e meio Ambiente (Semana da Geografia); Educar a população quanto à importância da sustentabilidade, dentre outras. Entende-se que as duas categorias criadas contemplam ações que tratam de todos os sete temas do PLS, indiretamente.

Tabela 2 Práticas sustentáveis x Percentuais

\begin{tabular}{lccc} 
Práticas Sustentáveis & Quantidade & Percentual \\
\cline { 1 - 1 } Água e esgoto & 26 & $8 \%$ \\
Coleta seletiva & 45 & $14 \%$ \\
Compras e contratações Sustentáveis & 29 & $9 \%$ \\
Deslocamento de pessoal & 21 & $7 \%$ \\
Educação ambiental & 59 & $19 \%$ \\
Energia elétrica & 33 & $10 \%$ \\
Material de consumo & 53 & $17 \%$ \\
Plano & 22 & $7 \%$ \\
Qualidade de vida no trabalho & 29 & $9 \%$ \\
\hline Total & $\mathbf{3 1 7}$ & $\mathbf{1 0 0 \%}$ \\
\hline
\end{tabular}

Fonte: Elaborada pelos autores.

Contabiliza-se, através da Tabela 2, que a maioria das práticas está na categoria Educação Ambiental (19\%). Em seguida revelaram-se as práticas voltadas para material de consumo (17\%); coleta seletiva (14\%); energia elétrica (10\%) e qualidade de vida no trabalho (9\%); água e esgoto (8\%). Deslocamento de pessoal e planos $(7 \%)$ foram os percentuais menos expressivos. 


\subsection{BENCHMARK DAS PRÁTICAS SUSTENTÁVEIS DAS UF’S BRASILEIRAS}

Após coletar e organizar as ações de DCC das UF's, observou-se que há inúmeras ações vagas, que não informam a maneira de como serão executadas. Por exemplo: 1) campanhas de conscientização de escolha de produtos sustentáveis para o setor de compras; 2) estimular, por meios de campanha de conscientização, o uso de copos reutilizáveis; e 3) promover campanhas de conscientização de energia elétrica. À vista disso, organizou-se com base na classificação da tabela 2, algumas ações diferenciadas, com o objetivo de construir um instrumento de fácil consulta para gestores universitários. No Quadro 2 encontra-se as melhores práticas identificadas.

Quadro 2 Melhores práticas identificadas

\begin{tabular}{|c|l|}
\hline UF & \multicolumn{1}{c|}{ Descrição da Ação } \\
\hline UNIFAL & $\begin{array}{l}\text { Realizar campanhas de conscientização sobre a redução do consumo de água junto aos } \\
\text { alunos, servidores, terceirizados e visitantes. }\end{array}$ \\
\hline UFS & $\begin{array}{l}\text { Aproximar a pesquisa e a extensão universitária aos desafios das questões da água e do } \\
\text { esgoto. }\end{array}$ \\
\hline UFSC & $\begin{array}{l}\text { Estimular o desenvolvimento de trabalhos acadêmicos que proponham soluções aos } \\
\text { problemas relacionados ao tema água e saneamento enfrentados pela esfera } \\
\text { administrativa da UFSC. }\end{array}$ \\
\hline UFRB & $\begin{array}{l}\text { Criar um espaço para discussões nas Redes Sociais com promoção de campanhas } \\
\text { educativas coma publicação de folder eletrônico, faixas e adesivos para coleta seletiva. }\end{array}$ \\
\hline UFC & $\begin{array}{l}\text { Fazer uma campanha para que os equipamentos de informática que não estão sendo } \\
\text { utilizados sejam devolvidos para o patrimônio, para que sejam classificados em } \\
\text { inservíveis e o restante seja destinado à doação, mediante convênio com escolas públicas. }\end{array}$ \\
\hline UFSC & $\begin{array}{l}\text { Criar uma plataforma visual/site para divulgar o sistema de resíduos sólidos e propiciar } \\
\text { sua interação com a comunidade universitária }\end{array}$ \\
\hline UFMS Compras e contratações sustentáveis \\
\hline UFSC & $\begin{array}{l}\text { Incentivar a participação dos pregoeiros em cursos de capacitação para o exercício de } \\
\text { suas atividades e a atenção aos critérios de compras e contratações sustentáveis, } \\
\text { extensivo a toda a equipe do Setor de Compras e demais membros do setor } \\
\text { administrativo que lidam com a catalogação de produtos e elaboração de Termos de } \\
\text { Referência. }\end{array}$ \\
\hline UFC & $\begin{array}{l}\text { Grupo "Carona UFC". Nele, os alunos se dividem entre alunos voluntários que oferecem } \\
\text { caronas de diversas partes de Fortaleza e alunos que não possuem carro. No mesmo } \\
\text { grupo, é disponibilizada uma planilha que visa à informatização desta iniciativa. Buscam } \\
\text { sistematizar o Carona UFC através da distribuição de adesivos aos voluntários como } \\
\text { forma de identificá-los e assegurá-los. } \\
\text { sustentáveis. } \\
\text { tecnologias que abordem o tema. } \\
\text { sustentáveis, através do estímulo ao desenvolvimento de trabalhos científicos e }\end{array}$ \\
\hline UFERSA administrativos para elaboração de editais para compras \\
\hline UFS
\end{tabular}




\begin{tabular}{|c|c|}
\hline UFC & Prever espaço para bicicletários nos prédios novos. \\
\hline \multirow[t]{2}{*}{ UFSM } & $\begin{array}{l}\text { Realizar licitação para aquisição das bicicletas. Difundir o uso de bicicletas para a } \\
\text { locomoção dos servidores, docentes e discentes no campus. }\end{array}$ \\
\hline & Educação ambiental \\
\hline UFMA & $\begin{array}{l}\text { Projeto de Comunicação para a Sustentabilidade: Estimular, por divulgação de autoria ou } \\
\text { por premiação, a participação de alunos e servidores na elaboração das campanhas. }\end{array}$ \\
\hline UFS & $\begin{array}{l}\text { Divulgar informações e recursos sobre sustentabilidade na orientação de novos } \\
\text { funcionários. }\end{array}$ \\
\hline UFS & Realizar programas educativos através da Rádio UFS. \\
\hline \multirow[t]{2}{*}{ UFTM } & $\begin{array}{l}\text { Elaborar cartilhas educativas visando a divulgação de informações ambientais e ações } \\
\text { sustentáveis para alunos, servidores e público externo. }\end{array}$ \\
\hline & Energia elétrica \\
\hline UFERSA & $\begin{array}{l}\text { Capacitar a equipe responsável pela elaboração de especificações técnicas para projetos, } \\
\text { construções, reformas e aquisição de bens e serviços que envolvam o consumo de energia } \\
\text { elétrica. }\end{array}$ \\
\hline UFMS & Capacitação de Gestão Energética Sustentável. \\
\hline \multirow[t]{2}{*}{ UFSC } & $\begin{array}{l}\text { Criar homepage direcionada a divulgação das informações do consumo de energia à } \\
\text { comunidade universitária. }\end{array}$ \\
\hline & Material de consumo \\
\hline UFG & Campanha de revisão dos documentos antes de imprimir. \\
\hline \multirow[t]{2}{*}{ UFMS } & Lançar a campanha "Adote uma caneca", afixando cartazes por todos os Campus. \\
\hline & Plano \\
\hline UFMA & Promover curso de capacitação para os representantes do PLS nas diversas unidades. \\
\hline UFS & Criar uma página específica para o plano. \\
\hline \multirow[t]{2}{*}{ UFTM } & $\begin{array}{l}\text { Implantar Caixinhas de Ideias Sustentáveis em locais estratégicos da universidade e } \\
\text { estimular a utilização do fale conosco, via web (página eletrônica do PLS). }\end{array}$ \\
\hline & Qualidade de vida no trabalho (QVT) \\
\hline UFRB & $\begin{array}{l}\text { Criar espaço no site da UFRB destinado a divulgar artigos e textos sobre temas } \\
\text { relacionados a qualidade de vida no ambiente de trabalho. }\end{array}$ \\
\hline UFSJ & Realizar palestras nos campi sobre o tema ergonomia e QVT. \\
\hline UFSJ & Realizar palestras nos campi sobre o tema saúde e alimentação. \\
\hline
\end{tabular}

Fonte: Elaborado pelos autores.

\subsection{AÇÕES DE DCC E SEUS INDICADORES}

Para que fosse possível identificar as práticas das UF's relacionadas ao requisito mínimo de DCC do PLS e seus respectivos indicadores, elaborou-se um questionário individualizado para cada UF que autorizou sua participação, no total de sete. Os questionários foram construídos tendo como base os PLS's e Relatórios de Acompanhamentos das UF's respondentes, contendo aproximadamente de 15 a 30 questões. Para cada ação identificada foi questionado se houve alteração no indicador e na meta informada e para aqueles que não possuíam informação sobre indicador e/ou meta, perguntou-se da existência de tais indicadores e alcance das metas.

Das 135 perguntas respondidas sobre ações de DCC, 69,6\% das UF's afirmaram possuir indicadores definidos, sendo que $1,5 \%$ não possuem e $28,9 \%$ não responderam. 
Também, verificou-se que a maior parte das metas $(46,7 \%)$ foram alcançadas. Não foram alcançadas $20,7 \% ; 17 \%$ não concluíram o período de implementação e $15,6 \%$ não possuem informações ou não responderam. No Quadro 4 estão apresentados os resultados dos questionários de cada uma das UF's que participaram da pesquisa. Ele demonstra que a maioria das UF's possui Relatórios de Acompanhamento. Observa-se, no entanto, que algumas não se encontram disponíveis no site oficial. Quanto aos indicadores, três UF's possuem indicadores para todas as práticas de DCC. Observa-se que as UF's apresentam dificuldade em cumprir as metas propostas, por conta dos baixos níveis percentuais alcançados.

Foi percebido, também, através das análises dos questionários aplicados que, grande parte das UF's possuem ações vagas. Alguns gestores desconhecem o que seja indicador ou o confundem com o conceito de meta. Porém, há aquelas que não apenas seguem a legislação, como também se aprofundam em temas e ações, e consideram que a atual crise financeira das UF's pode ser uma oportunidade de valorização do PLS, já que o mesmo têm como resultado final, a redução de custos operacionais das IES. Também foi possível verificar, de modo geral, algumas dificuldades vivenciadas pelas UF's com relação à gestão do PLS e na elaboração de Relatório de Acompanhamento, como o período de greve ocorrido, em 2015, nas UF's brasileiras.

Quadro 4 Resumo dos números de DCC

\begin{tabular}{|l|c|c|c|c|c|c|c|}
\hline & UF 01 & UF 02 & UF 03 & UF 04 & UF 05 & UF 06 & UF 07 \\
\hline Apresentam Relatório & Sim & Sim & Sim & Sim & Não & Não & Sim \\
\hline Metas & & & & & & & \\
\hline Alcançada & $54 \%$ & $33,4 \%$ & $53,6 \%$ & $11,1 \%$ & $71,5 \%$ & - & $93,3 \%$ \\
\hline Não Alcançada & $28 \%$ & - & $39,3 \%$ & $77,8 \%$ & $14,5 \%$ & $13,1 \%$ & $6,7 \%$ \\
\hline $\begin{array}{l}\text { Período de implementação não } \\
\text { concluído }\end{array}$ & $9 \%$ & $8,3 \%$ & $7,1 \%$ & $11,1 \%$ & $9,5 \%$ & $60,8 \%$ & - \\
\hline Sem informação/não respondeu & $9 \%$ & $58,3 \%$ & - & - & $4,5 \%$ & $26,1 \%$ & - \\
\hline Apresentam Indicadores & & & & & & & \\
\hline Sim & $68,1 \%$ & $25 \%$ & $100 \%$ & $66,7 \%$ & $100 \%$ & $43,5 \%$ & $100 \%$ \\
\hline Não & - & - & - & $11,1 \%$ & - & $52,2 \%$ & - \\
\hline Não respondeu & $31,9 \%$ & $75 \%$ & - & $22,2 \%$ & - & $4,3 \%$ & - \\
\hline
\end{tabular}

Fonte: Elaborado pelos autores.

\section{CONSIDERAÇÕES FINAIS}

Como forma de transformar a cultura nos órgãos públicos, foi criado o Plano de Gestão de Logística Sustentável (PLS). Sua criação se deu para que sejam estabelecidas 
práticas sustentáveis no interior dos órgãos públicos, ou seja, ações que desencadeiem a construção de um novo modelo de cultura nas organizações públicas ao incluir critérios de sustentabilidade. É através deste entendimento que o PLS abrange as Universidades Federais. Com a realização do trabalho foi possível compreender que a educação universitária é o processo pelo qual se reproduz, conserva, sistematiza, organiza, transmite e universaliza conhecimentos.

O Ensino Superior possui também a capacidade de oferecer conhecimentos técnicos e científicos ao corpo discente e também de despertá-los para questões ambientais e para a promoção da justiça socioambiental. Para tanto, entende-se que as ações de DCC são imprescindíveis para que as Universidades Federais possam alcançar seus objetivos de tornarem-se mais sustentáveis. A pesquisa teve início através da identificação de quais UF's possuem o PLS, para em seguida identificar as ações de DCC e classificar as práticas, de acordo com os sete temas mínimos. Também se aplicou questionários a cada uma das UF's participante da pesquisa a fim de conhecer os indicadores e metas adotadas por elas. E, finalmente, com o intuito de contribuir com as Instituições de Ensino Superior na elaboração e aprimoramento de seus PLS, aplicou-se a ferramenta do benchmark com as julgadas melhores práticas, além de um diagnostico da situação atual em relação aos indicadores adotados.

Mesmo diante do objetivo principal alcançado, esta pesquisa sofreu algumas limitações. Além da falta de literatura na área, verificou-se que das 63 Universidades Federais existentes no Brasil, apenas 22 delas possuem o Plano. Ou seja, mesmo sendo instituído por Decreto e já regularizado no âmbito nacional, o Plano ainda não tem sido adotado na maioria das Universidades Federais. Outra limitação é a falta de elaboração de Relatórios de Acompanhamento. Das 22 Universidades Federais pesquisadas, apenas 8 delas realizaram o Relatório de Acompanhamento, exigência que foi normatizada para ser cumprida ao final de cada ano, e que serve de instrumento de mensuração e de acompanhamento da evolução das boas práticas de sustentabilidade. Para estudos futuros, identificaram-se algumas oportunidades: verificar se as Universidades Federais que não possuem o PLS adotam algum Programa elencado na IN nº10/2012-MPOG, como o Programa Eficiência do Gasto Público, Programa Nacional de Conservação e Energia Elétrica, Agenda Ambiental na Administração Pública (A3P), Coleta Seletiva Solidária, Projeto Esplanada Sustentável e Contratações Públicas Sustentáveis. Também poderá investigar os reais motivos de determinadas Universidades Federais não possuírem o PLS, como mecanismo de gestão sustentável. E, por 
fim, analisar e levantar propostas para os outros três conteúdos mínimos do PLS, não aqui abordados.

Por fim, ao longo da pesquisa, observou-se que inserir a cultura da sustentabilidade nas Instituições de Ensino Superior, no Brasil não se trata de uma tarefa fácil, pois nota-se que mesmo sendo instituído por Decreto e com mais de três anos de implementação, menos da metade das UF's possuem o Plano e observa-se dificuldade também na elaboração de Relatórios de Acompanhamento. Entretanto, com o apoio da comunidade e dos dirigentes das Universidades e com mais investigações científicas voltadas a essa problemática, acredita-se ser possível, paulatinamente, mudar padrões voltados para o uso inapropriado dos recursos para um padrão sustentável. É importante que se possa enxergar o PLS não como um empecilho, mas sim como uma oportunidade de transformar a cultura também das Instituições de Ensino Superior, voltando-as para a sustentabilidade.

\section{REFERÊNCIAS}

ACSELRAD, H., HERCULANO. S, PÁDUA, J. A. Justiça Ambiental e Cidadania. Ed. Relume Dumará, Rio de Janeiro, 2004.

BRASIL. Acórdão n 1.752, de 29 de junho de 2011. Tribunal de Contas da União. Disponível em: $<$ http://jacoby.pro.br/novo/uploads/sustentabilidade/juris/eficientiza_o_energ_tica//tcu_ac _rd_o_n_1752_2011_plen_rio.pdf>. Acesso em: 13 out. 2015.

Constituição da República Federativa do Brasil. Senado Federal. Brasília, Distrito Federal, 1988.

Decreto 4.131, de 14 de fevereiro 2002a. Disponível em: < http://www.planalto.gov.br/ccivil_03/decreto/2002/D4131.htm>. Acesso em: 16 set. 2015.

Decreto 5.205, de 14 de setembro de 2004. Regulamenta a Lei $\mathrm{n}^{\mathrm{o}} 8.958$, de 20 de dezembro de 1994. Disponível em: <http://www.planalto.gov.br/ccivil_03/_ato20042006/2004/decreto/D5205impressao.htm>. Acesso em: 26 set. 2015.

Decreto 5.707, de 23 de fevereiro de 2006a. Disponível em: < http://www.planalto.gov.br/ccivil_03/_Ato2004-2006/2006/Decreto/D5707.htm>. Acesso em: 02 set. 2015.

Decreto 5.940, de 25 de outubro de 2006b. Disponível em: $<$ http://www.planalto.gov.br/ccivil_03/_Ato2004-2006/2006/Decreto/D5940.htm>. Acesso em: 16 set. 2015. 
Decreto 7.404, de 23 de dezembro de 2010d. Disponível em: < http://www.planalto.gov.br/ccivil_03/_ato2007-2010/2010/decreto/d7404.htm>. Acesso em: 01 jul. 2016

Decreto no 7.746, de 5 de junho de 2012a. Disponível em:

$<$ http://www.planalto.gov.br/ccivil_03/_ato2011-2014/2012/decreto/d7746.htm>. Acesso em: 21 abr. 2015.

Decreto 99.658, de 30 de outubro de 1990a. Disponível em: $<$ http://www.planalto.gov.br/ccivil_03/decreto/antigos/D99658.htm>. Acesso em: 08 abr 2015 .

Lei 8.112, de 11 de dezembro de 1990b. Disponível em:

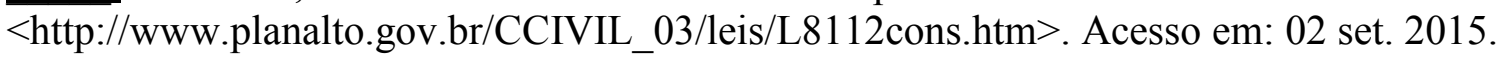

Lei 8.666, de 21 de junho de 1993. Disponível em:

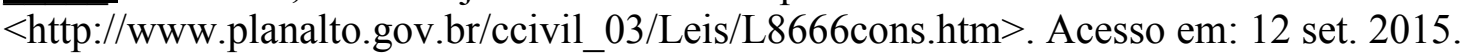

Lei 9.795, de 27 de abril de 1999. Disponível em:

$<$ http://portal.mec.gov.br/secad/arquivos/pdf/educacaoambiental/lei9795.pdf $>$. Acesso em: 26 set. 2015.

Lei $\mathbf{n}^{\mathbf{0} 9.605}$, de 12 de fevereiro de 1998. Disponível em:

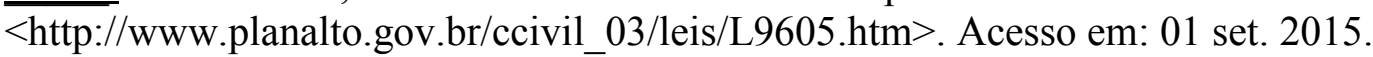

Lei 10.295, de 17 de outubro de 2001a. Disponível em:

$<\mathrm{http}: / / w w w . p l a n a l t o . g o v . b r / c c i v i l \_03 /$ leis/LEIS_2001/L10295.htm>. Acesso em: 16 set. 2015.

Lei 10.520, de 17 de julho de 2002b. Disponível

em:<http://www.planalto.gov.br/ccivil_03/leis/2002/L10520.htm>. Acesso em: 03 set. 2015.

Lei 12.187, de 29 de dezembro de 2009a. Disponível em:

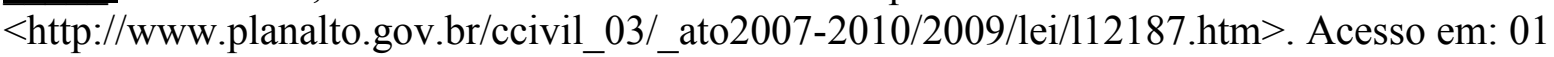
jul 2016.

Lei 12.305, de 02 de agosto de 2010a. Disponível

$\overline{\mathrm{em}:<\mathrm{htt}}$ ://www.planalto.gov.br/ccivil_03/_ato2007-2010/2010/lei/112305.htm>. Acesso em: 16 set. 2015.

Lei 12.349, de 15 de dezembro de 2010b. Disponível em:

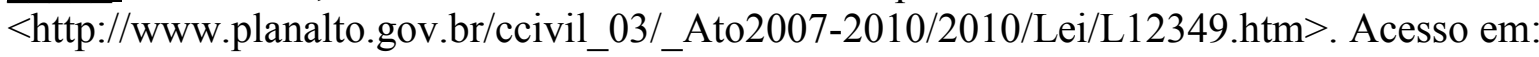
01 set. 2015.

. Ministério do Planejamento. Secretaria de Gestão. Produto 4: Guia referencial para medição de desempenho e manual para construção de indicadores. Brasília, DF. 2009b. 112 p. Disponível em: <http://www.gespublica.gov.br/biblioteca/pasta.2010-1208.2954571235/Guia\%20- 
\%20Indicadores\%20\%28versao\%20preliminar\%20Dez\%2009\%29.pdf $>$. Acesso em: 29 jul. 2015.

Resolução CONAMA n ${ }^{\circ}$ 275, de 25 de abril de 2001b. Disponível em:

$<$ http://www.mma.gov.br/port/conama/legiabre.cfm?codlegi=273>. Acesso em: 01 jul. de 2016.

Secretaria de Logística e Tecnologia da Informação do Ministério do Planejamento, Orçamento e Gestão. Instrução Normativa n $\mathbf{n}^{\mathbf{0}}$ 10, de 12 de novembro de 2012b. Disponível em: < http://www.mma.gov.br/images/arquivo/80063/141112_IN10.pdf >. Acesso em: 21 abr. 2015.

Secretaria de Logística e Tecnologia da Informação do Ministério do Planejamento, Orçamento e Gestão. Instrução Normativa n 1, de 19 de Janeiro de 2010c. Disponível em: $<$ https://www.cti.ufu.br/sites/cti.ufu.br/files/IN-SLTI-01-19Jan2010-SustentabilidadeAmbiental.pdf>. Acesso em: 01 set. 2015.

CAVEDON, F. S., VIEIRA, R. S. Socioambientalismo e Justiça Ambiental como Paradigma para o Sistema Jurídico: Ambiental: Estratégia de Proteção da Sóciobiodiversidade no tratamento dos conflitos jurídico-ambientais.

GUIMARÃES, M. Sustentabilidade e educação ambiental. In: Cunha, Sandra Baptista da; Guerra; Antônio José Teixeira (orgs). A questão ambiental: diferentes abordagens. 6. ed. Rio de Janeiro: Bertrand.

HAMMOND, Allen. et al. Environmental indicators: a systematic approach to measuring and reporting on environmental policy performance in the context of sustainable development. Washington, DC: World Resources Institut, 1995.

LEÃO, L. H. C.. Território e (in)justiça ambiental: uma agenda científica para a psicologia organizacional e do trabalho. Cadernos de Psicologia Social do Trabalho, 2013, vol. 16, n. 2, p. 183-198.

LOPES, J. C. J. Resíduos sólidos urbanos: consensos, conflitos e desafios na gestão institucional da Região Metropolitana de Curitiba - PR. 250f. Tese (Doutorado). Programa de Pós-Graduação em Meio Ambiente e Desenvolvimento, Universidade Federal do Paraná. Curitiba, 2007.

MARÍN, María Isabel Rivas. Modelo de sistema de gestión ambiental para formar universidades ambientalmente sostenibles en Colombia. Revista Gestion y Ambiente. Medellín. v. 14, n.1, p. 151-162, abr. 2011.

MEDEIROS JUNIOR, Geraldo José. Universidade e Responsabilidade Social. Revista Gestão Universitária na América Latina - GUAL. Florianópolis, Santa Catarina. 2004. MINISTÉRIO DO MEIO AMBIENTE. Conferência das Nações Unidas Sobre o Meio Ambiente e Desenvolvimento. Agenda 21 Global. Brasília, DF. 1995. Disponível em: < http://www.mma.gov.br/responsabilidade-socioambiental/agenda-21/agenda-21-global> Acesso em: 07 de jun. 2015. 
Agenda Ambiental na Administração Pública (A3 P). 5.ed. Brasília, DF. 2009. 100 p. Disponível em:<http://www.mma.gov.br/estruturas/a3p/_arquivos/cartilha_a3p_36.pdf $>$ Acesso em: 21/04/2015.> Acesso em: 21 abr. 2015.

MINISTÉRIO DO PLANEJAMENTO, ORÇAMENTO E GESTÃO. Portaria Interministerial $\mathbf{n}^{\mathbf{0}}$ 244, de 06 de junho de 2012. Projeto Esplanada Sustentável. Publicada no DOU de 08/06/12, seção I, página 137. Brasília, DF. 2012. Disponível em: $<$ http://www.orcamentofederal.gov.br/eficiencia-dogasto/Ptr_Intermin_244_de_060612.pdf $>$. Acesso em: 13 out. 2015.

PETRELLI, C. M.; COLOSSI, N.. A quarta via das instituições de ensino superior: a responsabilidade social. Revista Catarinense da Ciência Contábil. Florianópolis, Santa Catarina. vol. 5, n. 13, p.71-83, dez 2005/mar 2006.

SERVIÇO SOCIAL DA INDÚSTRIA. Departamento Regional do Estado do Paraná. Observatório Regional Base de Indicadores de Sustentabilidade - ORBIS. Construção e análise de indicadores. Curitiba: [s.n.], 2010.

SEVERINO, Antônio Joaquim. Metodologia do trabalho científico. 23. ed. rev e atual. São Paulo: Cortez, 2007. p. 304.

TAUCHEN, J. A. Um modelo de gestão ambiental para implantação em instituições de ensino superior. 149f. Dissertação (Mestrado) - Programa de Pós- Graduação em Engenharia, Universidade de Passo Fundo. Passo Fundo, RS. 2007.

TAUCHEN, J. A., BRANDLI, L. L. A gestão ambiental em instituições de ensino superior: modelo para implantação em campus universitário. Gestão e Produção, São Carlos. v. 13, n. 3, p. 503-515, set/dez. 2006. 